\title{
O PROFESSOR REFLEXIVO NO PROCESSO DE ENSINO APRENDIZAGEM DE LÍNGUA ESTRANGEIRA
}

\author{
Cláudia Caixeta da Silva \\ Elizandra Zeulli
}

\begin{abstract}
RESUMO: Este trabalho tem como objetivo discutir a prática do professor de língua estrangeira enquanto agente reflexivo no processo de ensino-aprendizagem em contraposição às ações do professor técnico. Delineou-se o perfil do professor reflexivo a partir de estudos desenvolvidos por Schön (1983, 1987), Dewey (1933, 1938), Zeichner (1996) entre outros, para posterior estabelecimento de um diálogo sobre o contexto da atuação e do papel do professor, da importância da sua postura crítica, de sua capacidade de avaliar, observar e propor soluções frente às dificuldades, que muitas vezes, podem ser consideradas instransponíveis. Considera-se relevante a relação entre a teoria e a prática como um processo contínuo e permanente na formação inicial, em serviço e continuada. Em suma, nesta investigação delineada como pesquisa bibliográfica, procurou-se pontuar os benefícios da prática reflexiva como ferramenta para o enfrentamento de problemas e situações adversas, sejam elas relativas às normas da instituição, às políticas educacionais, aos métodos, ou até mesmo dificuldades com a disciplina, interesse e aprendizado. Os primeiros resultados evidenciam a necessidade de reflexão sobre a prática e, a partir daí, a busca por aperfeiçoamento e formação continuada dos professores de língua estrangeira, tendo em vista uma docência de maior qualidade e que, por isso, garantirá resultados mais positivos no processo ensino-aprendizado.
\end{abstract}

PALAVRAS-CHAVE: Professor de língua estrangeira. Ação reflexiva. Formação

ABSTRACT the objective of this article is to discuss the foreign language teaching practice as a reflexive agent in the language learning process rather thans a technician. Among other researchers, we took Schön's (1983, 1987), Dewey's (1933, 1938), and Zeichner's (1996) studies to understand the reflexive thinking which conducts to the reflexive practice, crucial to deal with and find solution to problems which can be considered beyond solution at first sight. The close relation between theory and practice is also relevant in the permanent and continuous teachers' formation process. To sum up, this investigation classified as bibliographic research, aims at showing the benefits of the reflexive practice as a means to cope with difficulties in the foreign language teaching and learning demands, irrespective of relating to school rules, educational policies, methodologies, students' interest, motivation and learning abilities.

KEYWORDS Foreign language teacher - Reflexive teaching - Teacher formation

\footnotetext{
${ }^{1}$ Cláudia Caixeta da Silva - Universidade Federal do Triângulo Mineiro - UFTM, sclauca@gmail.com

${ }^{2}$ Elizandra Zeulli - Universidade Federal do Triângulo Mineiro - UFTM lizeulli@hotmail.com
} 


\section{INTRODUÇÃO}

Esta pesquisa teve início com questionamentos a respeito do que é ser um professor reflexivo e suas implicações para o processo ensino-aprendizagem.

Autores como Dewey (1959, 1933); Schön (1983, 1987, 1997, 2000); Perrenoud (1999), Zeichner (1996) desenvolveram trabalhos sobre o professor reflexivo. A partir das leituras realizadas, buscou-se discutir e compreender o significado de ser um professor reflexivo, para, a partir daí, discutir a prática do professor de língua estrangeira, doravante LE, enquanto agente reflexivo no processo de ensino-aprendizagem, despertando o entendimento crítico-reflexivo em sua prática, delineando benefícios alcançáveis a partir dela. Assim, este trabalho justifica-se por questionar a atuação do professor de LE, em especial a prática reflexiva, pontuando os benefícios dessa prática como ferramenta para 0 enfrentamento de problemas e situações adversas, sejam elas relativas às normas da instituição, às políticas educacionais, aos métodos, ou até mesmo às dificuldades com a disciplina, interesse e aprendizado.

\section{A COMPREENSÃO DO QUE SIGNIFICA SER UM PROFESSOR REFLEXIVO}

Nesta seção, apresenta-se e discute-se o referencial teórico adotado. Para Dewey (1959:38-41) uma ação reflexiva, apresenta três atitudes essenciais à ação reflexiva:

1. Espírito aberto: disponibilidade para considerar as críticas recebidas, estar preparado para se questionar e reavaliar seu posicionamento;

2. Responsabilidade: cuidadosa consideração sobre as consequências de sua ação, pois ela influenciará na formação e concepção de mundo do aluno, no seu desenvolvimento intelectual, nas suas oportunidades de vida.

3. Dedicação: estar envolvido com sua prática, engajar-se efetivamente no processo reflexivo. 
De acordo com os estudos de Dewey (1959) um professor reflexivo é o que participa ativamente do processo de ensino-aprendizagem com responsabilidade, preocupado com a própria formação e com a de seus alunos, ou seja, é aquele verdadeiramente comprometido com a prática educacional.

Dewey (1933) estabelece ainda uma importante distinção entre duas ações que bem distinguem uma ação reflexiva daquela que não o é:

- Ação de rotina - guiada principalmente por impulso, tradição e autoridade. É a maneira particular como a escola vê e define um problema - código coletivo daquele lugar: "Aqui nós fazemos as coisas assim." Não se considera que aquela maneira de ver o problema é apenas uma das possíveis.

- Ação reflexiva - envolve uma consideração cuidadosa, ativa e persistente das razões que sustentam qualquer crença ou prática e sobre as futuras consequências a que elas possam levar. Não se trata de uma série de passos ou procedimentos a serem usados pelo professor.

Para Dewey (1933) a "ação de rotina" significa que muitas vezes profissionais e instituições não estão dispostos a "refletir", questionar, discutir ou até mesmo repensar uma determinada situação ou ação, apenas agem de forma autoritária, impositiva. Já a "ação reflexiva" pressupõe pensamento, diálogo, flexibilidade, isto é, há espaço para reflexão e crítica, elementos essenciais para a construção de um espaço consciente, responsável e comprometido com o processo de ensino e aprendizagem. A ação reflexiva, segundo Schön (1983, 1987, 1997 e 2000), ocorre antes, durante e depois da ação. Configura-se como um processo completo que visa a identificar e avaliar, com um olhar crítico, as atividades e os procedimentos desde a preparação até sua efetivação e análise de seus efeitos no contexto de sala de aula.

Dessa forma, de acordo com Schön (1983, 1987, 1997 e 2000), a ação reflexiva pode ser observada em três momentos distintos:

a. O que ele chama de reflexion-on-action, é a reflexão que ocorre em dois momentos: antes e depois da ação - quando primeiramente planejamos a aula, pensamos na abordagem a ser utilizada, no conteúdo a ser ministrado, na turma que 
o receberá e, posteriormente, quando reavaliamos e consideramos a maneira como a ação planejada efetivamente ocorreu.

b. Já a reflexion-in-action, é a que ocorre durante a ação. São os ajustes necessários, enquanto lecionamos, que visam ao melhor aproveitamento da proposta planejada, frente a situações inesperadas, não contempladas quando da preparação: alguma reação do aluno ou dificuldade na compreensão do conteúdo, por exemplo.

Outras duas contribuições importantes na caracterização do professor reflexivo vêm de Perrenoud (1999) e de Zeichner (1996). Perrenoud (1999) afirma que:

O profissional reflexivo é aquele que aceita fazer parte do problema, reflete não só sobre os recursos materiais e as pessoas que fazem parte do meio educacional como também sobre a forma de superar problemas e limitações do meio.

Percebe-se que Perrenoud (1999) entende que o profissional reflexivo é o que está, de fato, engajado no meio educacional, disposto a enfrentar os desafios e a superar as dificuldades, visando a um processo de ensino - aprendizagem consciente, responsável e eficiente.

Corroborando esse posicionamento, Zeichner (1996), enfatiza cinco pontoschave de um professor reflexivo:

- examina, contextualiza e procura resolver os dilemas da prática de sala de aula;

- $\quad$ está consciente de suas questões e suposições, valores que ele traz em sua prática;

- $\quad$ está atento ao contexto institucional e cultural no qual ele leciona;

- participa do desenvolvimento curricular e ações de mudanças na escola;

- $\quad$ assume responsabilidade pelo próprio desenvolvimento profissional.

É ponto chave entre todos os pesquisadores mencionados neste trabalho, a característica do professor reflexivo como aquele que se envolve em sua prática docente de uma maneira consciente, responsável e crítica. Vale salientar, ainda, que toda a ação do professor reflexivo é pensada, adequada e adaptada ao contexto a 
ser empregada, sempre considerando os participantes pertencentes a esse contexto de ensino-aprendizagem.

\section{ASPECTOS METODOLÓGICOS E APRESENTAÇÃO DOS RESULTADOS}

Esta pesquisa caracteriza-se como uma pesquisa bibliográfica por estar embasada nos estudos de autores como Dewey (1933, 1959), Shön (1983, 1987), Perrenoud (1999) entre outros; procurou-se utilizar um referencial teórico para auxiliar nas respostas às três perguntas de pesquisa que nortearam este trabalho:

$>\quad$ Qual é a diferença entre o professor técnico e o professor reflexivo?

O que é ser um agente reflexivo na prática docente de LE e por que sêlo?

$>\quad$ Quais as dificuldades do professor de LE para exercer a prática reflexiva?

Apresentadas as perguntas de pesquisa, objetiva-se agora respondêlas com base nos pressupostos teóricos já mencionados e discutidos neste trabalho. A apresentação dos resultados encontra-se de acordo com a ordem das perguntas de pesquisa.

$>\quad$ Qual é a diferença entre o professor técnico e o professor reflexivo?

O professor técnico (Zeichner, 1996) considera uma situação de conflito sob o ponto de vista de que o problema é com o outro; ele não é parte do problema, tampouco da solução, conforme postura do professor reflexivo. Não leva em consideração o contexto da sala de aula e tampouco a forma como a realidade sociocultural do aluno pode interagir nesse contexto. Decide agir em situações de crise aplicando técnicas, receitas, fórmulas que não consideram o contexto específico. O professor técnico tenta alterar o comportamento do aluno sem avaliar em profundidade a situação que o leva a determinada postura. Faz o que os outros, fora da sala de aula, querem que ele faça e jamais leva em consideração as necessidades do grupo com o qual trabalha. Esse professor age guiado por suposições, crenças sem jamais questioná-las. 
Já o professor reflexivo (Zeichner, 1996), pergunta a si mesmo sobre os possíveis fatores geradores de conflito, de dificuldades e busca recursos que possam auxiliá-lo tanto na compreensão do processo em si, quanto na estruturação de planos de ação e intervenção no problema específico. Questiona os valores e objetivos intrínsecos nas soluções escolhidas e examina as próprias motivações e o contexto em que o problema ocorre; questiona suas próprias crenças e orientações. O professor reflexivo assume responsabilidade pela sua ação.

Como se pode observar, a postura reflexiva leva o professor a voltar-se para a própria prática, reavaliar suas crenças e motivações, perceber a sua sala de aula e alunos, singularmente, para propor, agir, intervir e transformar.

É reconhecível a forte influência que os cursos de idiomas têm exercido no ensino de línguas aqui no Brasil, treinando professores dentro do perfil por eles (pelos cursos) aprazado, definindo-se, a partir daí, a conduta do professor, metodologias de abordagem de ensino condizentes com o curso, com o método ou, mesmo, com a franquia adotada. Nesses ambientes é praticamente nula a presença da reflexão, que dá lugar à técnica. Temos aí grande fonte geradora de professores técnicos em contraposição aos professores reflexivos.

Infelizmente não é apenas nos ambientes de cursos de idiomas que a falta de reflexão está presente: sabe-se que os cursos de formação de professores de línguas estrangeiras têm deixado a desejar em seus currículos, por não proporem atividades de cunho reflexivo.

$>\quad$ O que é ser um agente reflexivo na prática docente de LE e por que sêlo?

Segundo Zeichner, (1996) a maneira pela qual o professor lida com os problemas que tem em sala de aula resulta da forma como ele elabora, vê o problema que se apresenta. Assim, é essencial que se faça a seguinte pergunta: o que norteia a maneira pela qual vejo e elaboro um problema? O que sustenta a minha ação? Só assim posso acertar contas com as minhas crenças, com a minha própria trajetória de aprendizado e, a partir daí, abrir possibilidades novas de ver uma situação de conflito e, consequentemente, lograr sucesso na mediação da solução.

Para o efetivo ensino-aprendizado de LE, é necessário reconhecer e identificar fatores que dificultam ou colaboram com o aprendizado de LE, como, por 
exemplo, os aspectos individuais na aquisição de LE, como identidade, identificação, aspectos afetivos, culturais e sociais, idade, estratégia de aprendizado, para mencionarmos alguns dos itens mais abordados nas pesquisas relativas à aquisição de LE. É relevante considerar, também, o local onde a língua alvo está sendo ministrada, se é uma escola de idiomas ou escola regular secundária ou mesmo faculdade ou universidade, bem como o propósito para o qual ela está sendo ensinada, se é a aquisição da língua propriamente dita ou apenas o seu uso instrumental.

$>$ Quais as dificuldades do professor de LE para exercer a prática reflexiva?

Assumir responsabilidade pelo próprio processo de desenvolvimento e crescimento profissional, bem como pelas decisões tomadas exige posicionamento, o que implica assumir riscos. Parece fácil cruzar os braços diante das dificuldades: treinamento de capacitação em institutos de idiomas onde não há espaço para questionamentos, singularidades; metodologia própria da instituição a ser seguida, sem observância de características individuais dos alunos; pressão exercida pela escola no cumprimento do cronograma e programa; número de alunos em sala; nível de expectativa de conteúdo divergente daquele oferecido; exigências dos pais de alunos; dificuldade de adequação da abordagem pedagógica ao contexto em que a LE é ministrada; o material didático utilizado ou a falta do mesmo, bem como de outros recursos como, por exemplo, equipamento eletrônico e de mídia; carga horária insuficiente, entre outros problemas. Para Dewey (1933), a ação reflexiva é uma forma holística de encarar e responder a problemas; é uma maneira de ser como professor. É recusar o "não" como resposta, sem que antes tenha investigado, ponderado, tentado, de todas as formas cabíveis, encontrar uma solução para o dilema, encarando-o sob diferentes prismas: seja o dilema de ordem física, material, cognitiva, metodológica, afetiva, político-educacional ou mesmo técnica. Estabelecendo uma importante relação dialógica entre a teoria e a prática, 0 professor reflexivo, em sua formação inicial, em serviço e continuada, torna-se investigador de sua própria prática e passa a ser professor-investigador - professor pesquisador. 


\section{CONSIDERAÇÕES FINAIS}

Os primeiros resultados evidenciam a necessidade de refletir sobre a prática e, a partir daí, buscar aperfeiçoamento e formação continuada dos professores de língua estrangeira, tendo em vista uma docência de maior qualidade que, por isso, garantirá resultados mais positivos no processo ensino-aprendizagem.

Para trabalhos futuros, pretende-se realizar pesquisa de campo, com utilização de coleta de dados a partir de: questionários, entrevistas, gravações, entre outros instrumentos; para evidenciar as ações do professor e estabelecer um diálogo contínuo entre a teoria e a prática, partindo do princípio que a formação do professor, seja ela inicial ou continuada, deve ser embasada em atividades de caráter crítico reflexivo para melhor adequar-se ao contexto de sala de aula e à realidade social na qual os alunos estão inseridos.

\section{REFERÊNCIAS}

DEWEY, J. Como pensamos. Trad. H C Campos. São Paulo: Companhia Editora Nacional, 1959.

DEWEY, J. How we think. Chicago: Henry Regnery, 1933.

MARVIN F. \& ANDREWS, I. (orgs.) Staff Development For School Improvement. New York. The Falmer Press, 1987.

PERRENOUD, P. Formar Professores em Contextos Sociais de Mudança - Prática Reflexiva e participação crítica. Trad. Denice B. Catani. Revista Brasileira de Educação, Set/ Out/ Nov/ Dez, 1999. n. 12. págs. 5-21.

SCHÖN, D.A. The Reflective Practitione - How professionals think in action. New York: Basic Books, 1983.

. Educating the reflective practitioner: Toward a new design for teaching and learning in the professions. San Francisco: Josey-Bass Publishers, 1987.

SCHÖN, D. A. Formar Professores como Profissionais Reflexivos. In: Antônio Nóvoa (coord). Os professores e a sua formação. Lisboa: Publicações Dom Quixote, 1997. . Educando o Profissional Reflexivo: Um novo design para o ensino e a aprendizagem. Trad: Roberto Cataldo Costa. Porto Alegre: Artmed, 2000. 
ZEICHNER, K. A formação reflexiva de professores: ideias e práticas. Lisboa: Educa, 1993.

ZEICHNER, K. M. Reflective teaching: an introduction. Mahwah: Lawrence Erlbaum 1996.

Recebido para publicação em: 20/12/2009

Aceito: 02/07/2010 